\title{
Theory and Analysis of Three Phase Induction Motor using Written Pole Technology
}

\author{
Kishor S. Deshmukh ${ }^{1}$, Dr. Prof. Kamal Bansal ${ }^{2}$, Dr. Atul Killedar ${ }^{3}$ \\ ${ }^{I}$ PhD Scholar, Electrical and Electronics Engg., University of Petroleum and Energy Studies, Dehradun \\ ${ }^{2}$ Dean and Professor, College of Engineering, University of Petroleum and Energy Studies, Dehradun \\ ${ }^{3}$ Manager, Chemical Technology, Vishay Components India Pvt. Limited, Pune
}

\begin{abstract}
Three phase induction motors are employed in almost all the industries because of its simple construction and easy operation. Efficiency of the induction motor is affected by its fixed losses and variable losses which mainly depend on the input supply voltage and load current respectively. An attempt is made to minimize the iron losses by using the permanent magnet ferrite. A new Three Phase Induction Motor Using Written Pole Technology is proposed in this paper whose stator consists of two three phase windings accommodated in the same core and rotor is used as squirrel cage rotor with ferrite material on its periphery. Shaft loads are categorized as low, medium and high, Stator coils are energized through a controller based on the load demand. When compared to conventional induction motor, the motor efficiency and power factor are improved. Another approach of this machine is that the ferrite layer on the rotor periphery will reduce the motor losses which results in improving the motor efficiency. In this motor, one windings (main winding) is designed for the 238 volt ac voltage while the second winding (exciter winding) is designed for 8 volt ac voltage. Experimental result ensures the considerable increase in the efficiency and power factor.
\end{abstract}

Keywords: Three Phase Induction Motor Using Written Pole Technology, Main Winding, Exciter Winding, Control circuit for Optimum utilization.

\section{Introduction}

Induction motors are employed in Textile mills, Agriculture and almost all the manufacturing industries to drive the loads because of its rugged construction and ease operation. The major limitation of induction motor is its efficiency and power factor. These two parameters depend on the shaft load. In conventional induction motor, only mechanical output is available and hence, its power factor and efficiency is limited. Written pole induction motor with dual stator winding would be the better choice to overcome these limitations. Written-Pole Motors offer a revolutionary method for powering large horsepower applications in locations where only single-phase power is available. The Written-Pole motor is a hybrid concept, which utilizes basic concepts from induction, hysteresis and permanent magnet motors, with several important distinctions. The primary feature which differentiates Written-Pole motors from more conventional designs is a continuous layer of ferrite magnets on the surface of the rotor, along with a high-density exciter winding contained within the stator winding. This unique design matches the pole structure of the rotor to the rotational speed of the motor. The result is a motor that combines the desirable starting characteristics of a high-slip, high-power factor cage motor with the energy-efficient operation of an AC permanent magnet motor-- without relying on power electronics, reduced voltage starters or phase converters [1].

Dual stator induction motor became popular since 1930 . When a three phase supply is applied to one of the stator windings, a revolving magnetic field of constant magnitude is developed in the air gap and this field is shared by both the windings [2]. The various possibilities in the design modification, speed control, efficiency, power factor improvement of induction motor and double winding induction motors are discussed below. Dual stator induction motor stator with two separate windings wound for a dissimilar number of poles is fed from an independent variable-frequency variable-voltage inverter.This drive offers advantages as speed sensor less operation, Zero speed operation is achieved by independently controlling the two sets of stator current and hence, maintaining a minimum electrical frequency independent of mechanical speed. This drive is suited for either constant volts per hertz or filed oriented operation. Circulating harmonics currents are eliminated by the dissimilar number of poles [3]. Three-phase induction motors are designed to meet high starting torque, good operating efficiency and power factor. Optimization design of three-phase induction motor is formulated as a nonlinear multivariable programming problem to meet the above requirements. The simulated annealing algorithm was used to obtain an optimum design [4]. Any significant improvement in the operating efficiency of induction motor will be effort at energy conservation. The optimized design of induction motor can be obtained using Rosenbrock's method to minimize the cost of active materials, the annual energy consumed and the total annual cost [5]. The stator of a double winding induction motor can be connected in star and delta, thereby active resistance by $11 \%$ and inductance by $13 \%$ can be reduced. The active resistance decreases to considerable 
value and hence copper losses are decreased. DWIM has increase of output power and torque of $10 \%$ and starting torque reduced by $3.5 \%$ [6]. A $3.7 \mathrm{~kW}$ three phase induction motors are widely used in agriculture and industries. During rewinding process, efficiency get reduced by five percentage points due to improper rewinding process in which the winding conductor size is reduced by 1 SWG or by reducing number of turns from the winding specification. This improper rewinding practice results in reduction of torque per ampere and increase in winding temperature for the given load. [7]. Efficiency of the induction motor can be optimized even at lightly loaded condition by means of TRIAC fed drive. Input voltage is adjusted based on the optimalefficiency and power factor. More than $10 \%$ efficiency improvement is possible even at one fourth of the full load [8]. Dual stator induction motor suggested for energy conservation consists of two sets of RUN windings. The main RUN winding is energized to have sufficient MMF in order to produce sufficient magnetic flux and to operate the motor at light loads with good power factor. In this machine reduced power is applied to the second set of RUN winding and hence, the power consumed due to eddy currents, copper losses and poor power factor are considerably reduced [12]. The efficiency of an induction motors ranges between 0.75 and $22 \mathrm{~kW}$ can be improved by means of die cast copper instead of aluminium cage rotor with premium steel core [13]. In multi flux level of a three-phase squirrel-cage induction motor, the efficiency and power factor can be both maximized as a function of load. The stator winding with two sets of turns, shares the same positions in the stator slots. Among all the possible stator winding connections, six modes were selected and analyzed [16]. Efficiency of an induction motor can be improved by cutting the predefined arc-section of the rotor. Air gap over a periphery will not be uniform and causes edge effect. The redesign is focused on construction of the rotor with novel windings configurations [17]. Optimal values of induction motor design parameters can be determined using Particle Swarm based approach to three-phase Induction Motor based on particle-swarm-optimization (PSO) technique. This method shows improvement in efficiency, active material cost, and performance under starting and full load conditions [18]. Dual stator induction motor can be operated in power balancing mode and maximum efficiency mode for effective utilization of the machine. Second set of stator winding can feed electrical loads, thereby power factor and efficiency is improved [19].

\subsection{Representation of the Proposed Scheme:}

\section{Machine Model}

The Three Phase Induction Motor with Written Pole Technology consists of two three phase stator windings and the ferrite layer on the rotor periphery. The windings are arranged in the same stator core. The principle of operation of a Three Phase Induction Motor Using Written Pole Technology depends on one set of winding which is connected across a three phase supply and revolving magnetic field of constant magnitude is developed in the air gap. The same is utilized by the stator winding to work as an induction motor to meet mechanical load while, a three phase EMF is induced in the other two sets of winding to which electrical load can be connected that works as an Induction Alternator. The $238 \mathrm{~V}$ winding is connected across the supply till the rated speed is attained. Then based on the shaft load, the respective coils are energized. The exciter winding is wound on three different stator teeth instead of stator slots of induction motor. Rated voltage is applied when the machine is started and when the machine is operated above the two third capacity of the rated current. Exciter Winding is used for a wide range of speed control applications. By controlling the voltage applied to the second winding, the rotor speed can be controlled. The machine has a similar speed control characteristics to that of a slip ring induction motor [10].The pictorial representation of three phase induction motor with written pole technology is shown in the Figure.1.The terminal box consists of three sets of six terminals of three stator windings. While one set of winding i.e. main winding is energized with 238 volt and the second winding i.e. exciter winding is energized with 8 volt high frequency ac supply.

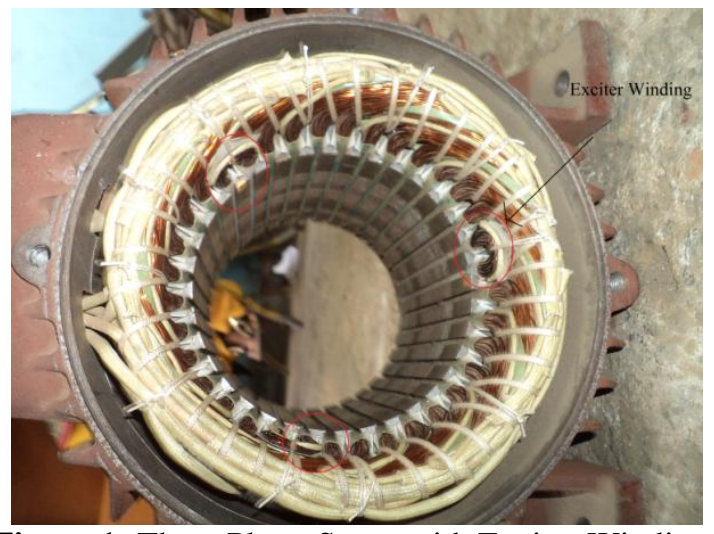

Figure 1: Three Phase Stator with Exciter Winding. 


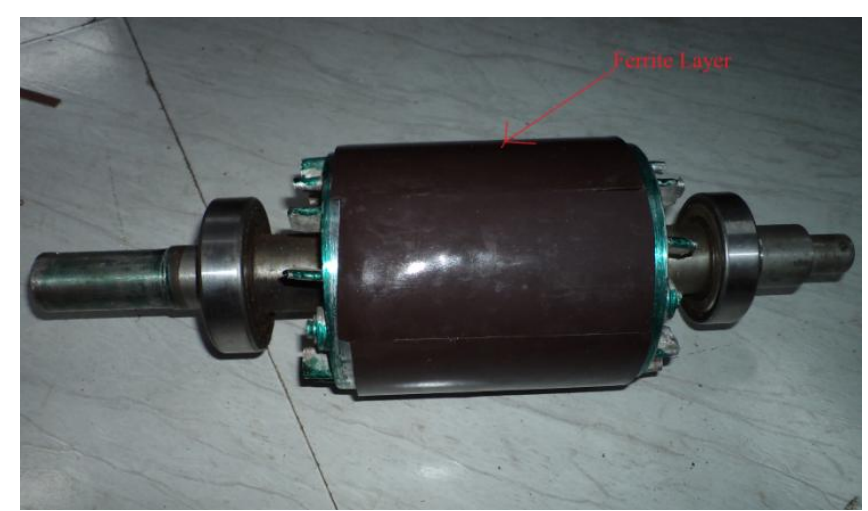

Figure 2: Three Phase Squirrel Cage Rotor with Ferrite Layer

\subsection{Design Considerations:}

The design of the three stator three winding induction motor is affected by various constraints such as thermal limit, overload capacity and utility of stator slots. The energy conserving three stator winding induction motor is ideal to be used for low power operations due to the limitation in thermal insulation value. The value of air gap flux density is large which determines large overload capacity. The proposed model uses semi-enclosed deeper slots. The stator of three phase induction motor with written pole technology consists of two sets of three phase stator windings, one placed on stator slots while second wound on stator teeth. The suggested design is suitable for electric/hybrid vehicles, aerospace applications, ship propulsion etc. Since deeper slots are preferred for the design, the reactance offered will be considerable.

\subsection{Design Description of the proposed Three phase Induction Motor with Written Pole Technology:}

$0.75 \mathrm{~kW}$ and $2.2 \mathrm{~kW}$ three phase induction motors are widely used for commercial applications. As a proof for the discussion, a $0.75 \mathrm{~kW}, 415 \mathrm{~V}, 4$ - pole, 3-phase Squirrel Cage Three Stator Winding Induction motor has been designed, fabricated and tested. M45 silicon alloy steel stampings are used for stator core. Stator coils are insulated with F-Class insulation. The technical details of three phase induction motor with written pole technology are given below:
Number of stator slots
$=36$
Number of rotor slots

$$
=28
$$$$
=115 \mathrm{~mm}
$$
$\begin{array}{ll}\text { Diameter of the bore } & =115 \mathrm{~mm} \\ \text { Length of the bore } & \end{array}$
Magnetic loading $\quad=0.45 \mathrm{~Wb} / \mathrm{m}^{2}$
Electrical loading $\quad=23000 \mathrm{ac} / \mathrm{m}$
Turns per phase of $238 \mathrm{~V}$ winding $=240$
Conductors per slot for $238 \mathrm{~V}$ winding $=40$
Conductors per teeth for $8 \mathrm{~V}$ winding $=20$
Slot area
Conductor area

$$
\begin{aligned}
& =39.59 \mathrm{~mm}^{2} \\
& =15.83 \mathrm{~mm}^{2}
\end{aligned}
$$

\section{Experimental Investigations}

In order to evaluate the performance of a three phase induction machine using written pole technology, there are various indirect and direct methods that are available. Rapid full load efficiency evaluation of three phase induction motors is using the synthetic loading technique with the help of a digital signal processor (DSP) controlled high switching frequency power electronic inverter synthetically loading the induction machine without the need to connect a load to the machine's drive shaft. This method considerably reduces the testing time compared with conventional methods of efficiency measurement and the accuracy of the result is maintained. This method can also directly quantify rotational losses of the induction motor under test [11]. The various direct and indirect methods of testing of induction motor that are available. By using Artificial Intelligence (AI) techniques such as artificial neural network (ANN), fuzzy logic, expert systems and nature inspired (NIA), Genetic algorithm and differential evaluation, energy optimization and design modification of induction motor is possible [14]. One of the methods to improve the Power Factor of three phase induction motor is through Power Factor Controller (PFC) with Programmable Logic Controller (PLC) in which the voltage to frequency ratio is maintained constant in order to obtain a maximum torque. To minimize the pseudo oscillation and harmonics, Zero voltage switching of static switches is allocated in the control algorithm [15]. 
In order to evaluate the performance characteristics of a designed three phase induction motor with written pole technology, a series of testing has been carried out. Experimental set up with mechanical loading is shown in Figure 3 and Figure 4.
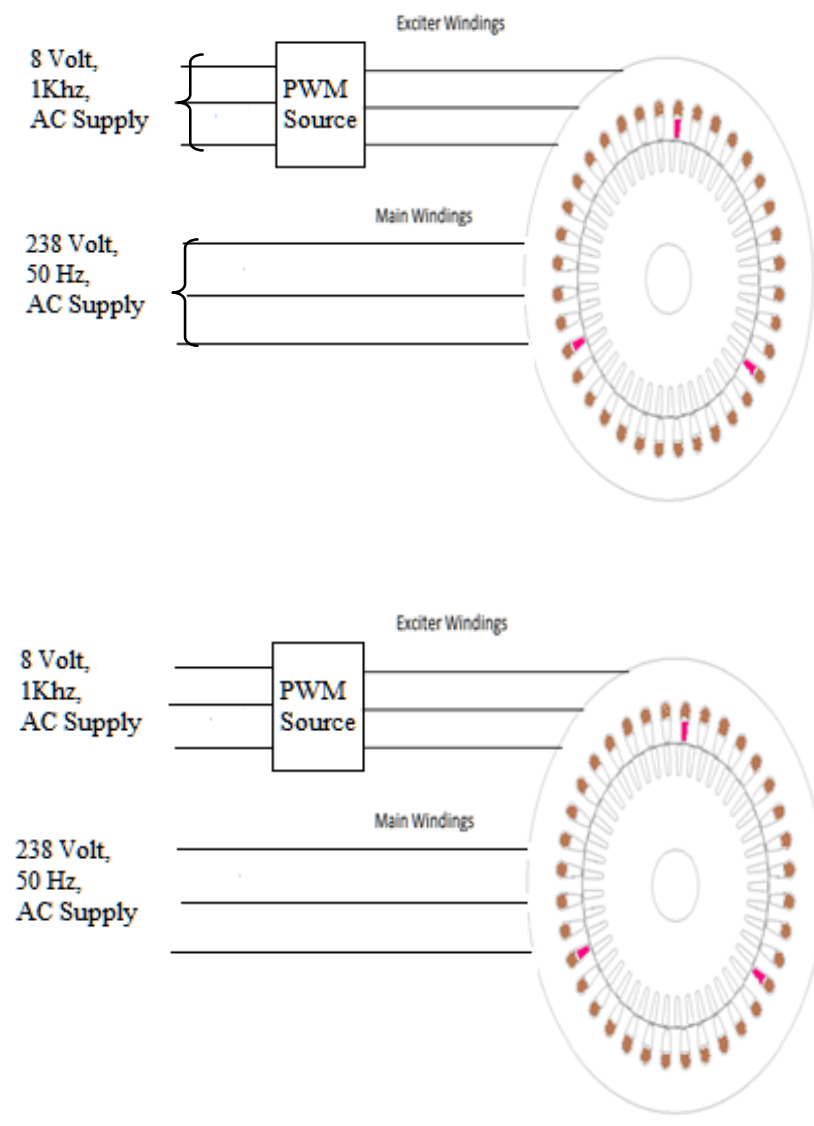

Figure 3: Circuit for Experimental Setup.

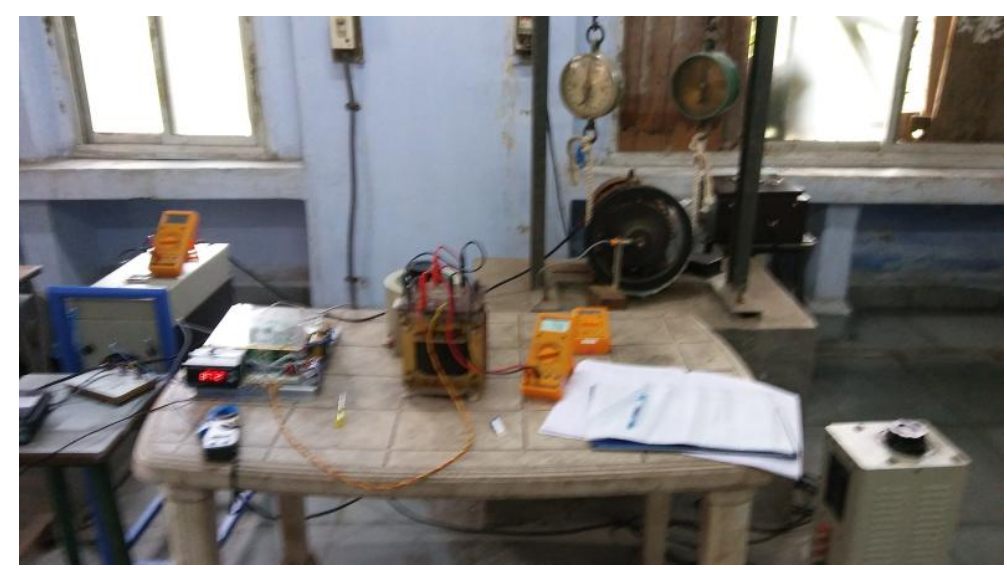

Figure 4: Equipments for experimental Setup

\subsection{Load test on $238 \mathrm{~V}$ on main winding and $6 \mathrm{~V}$ on exciter winding with high frequency ac supply :}

In order to analyze the performance of induction motor for $238 \mathrm{~V}$ for main winding and $8 \mathrm{~V}$, high frequency ac supply for exciter winding, a load test is carried out. The motor characteristics when excitation winding turned are shown in Figures 5 to 7. The performance of the three winding induction motor with written pole technology is studied for different excitation voltages and frequencies varies from 0 to 8 Volt and $50 \mathrm{~Hz}$ to $1 \mathrm{KHz}$ respectively. 


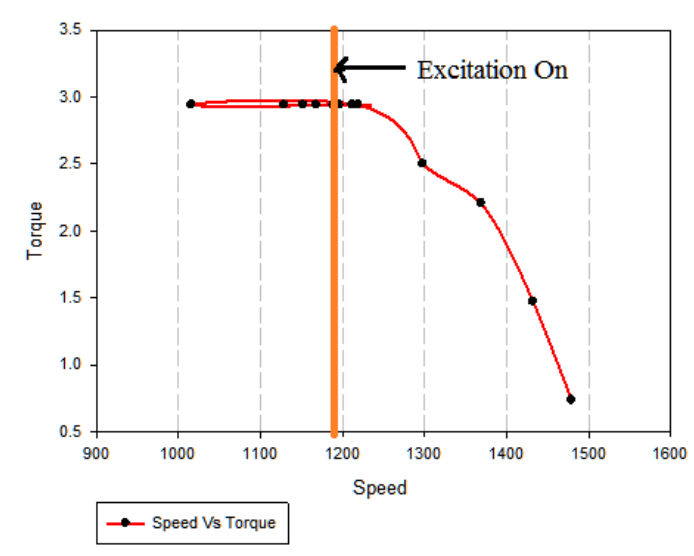

Figure 5: Speed Vs Torque Characteristics

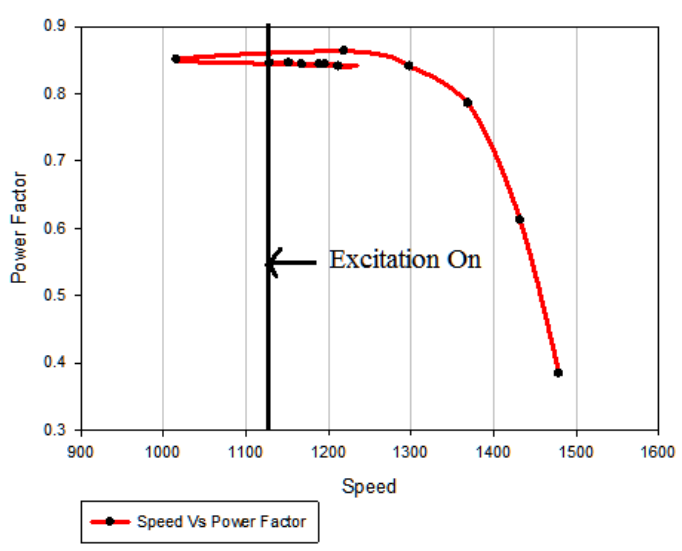

Figure 6 : Speed Vs Power Factor Characteristics

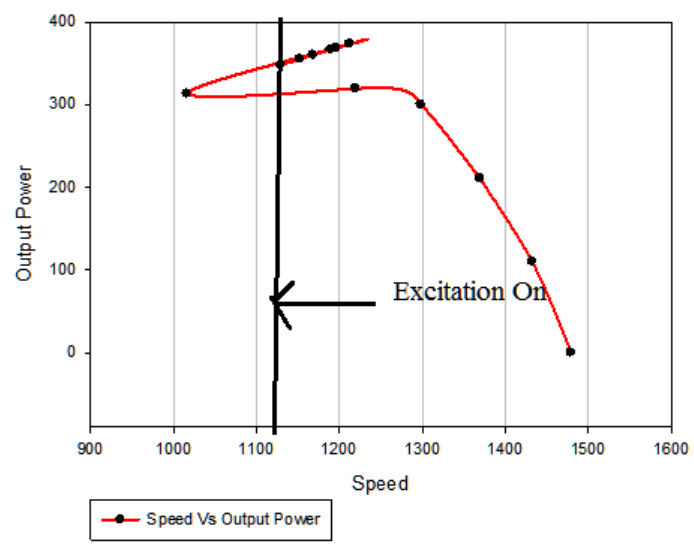

Figure 7 : Speed Vs Output Power Characteristics

\section{Conclusion}

A $0.75 \mathrm{~kW}, 3$-phase, 4-pole, $1440 \mathrm{rpm}$, Three phase induction motor with written pole technology has been designed, fabricated and tested successfully. The experimental results illustrate the improvement of Torque and power factor over the conventional induction motors. When motor rotates with main winding of $238 \mathrm{~V}$ supply, exciter winding unexcited, motor gives less speed range with higher $\%$ slip and high line current but when exciter winding is excited with high frequency, motor rotates with wide speed range at lower slip and lower line current. The efficiency and the power factor of motor are improved. From the other mode of operation, by utilizing the electrical output from the exciter windings to feed electrical loads, the industry's dependency on separate supply to the loads is reduced. The three winding induction motor can be employed, 
where the induction motor runs continuously for a longer period of time like textile industries and manufacturing units. The output power from the exciter winding can be used for charging the batteries, thereby allowing the UPS system to supply lighting loads.

\section{References}

[1]. S. Hoffman, B. Banerjee, and M. Samotyj, "Written-pole Revolution,” IEEE Power Eng. Rev., pp. 6-9, 1997.

[2]. P.L. Alger, E.H.Freiburghouse and.D.Chase, "Double windings for flexible alternators", AIEE Transactions, Vol.49, January 1930, pp. $226-244$

[3]. Alfredo Munaz-Garcia, Thomas A.Lipo, "Dual stator winding Induction Machine Drive", IEEE Transactions on Industry Applications, Volume 36, Issue 5, Sep/Oct 2000 pp.1369 - 1379.

[4]. Bhuvaneswari, R., Subramanian, S. (2005), "Optimization of three phase induction motor design using simulated annealing algorithm", Electric Power Components and Systems, Vol. 33, pp.947-56.

[5]. Murthy, S.S., Singh, B.P." Power Electronics, Drives and Energy Systems for Industrial Growth", Proceedings of the 1996 International Conference on Volume 1, Issue, 8-11 Jan 1996, pp.458 - 462 vol.1

[6]. Luan Ahma, Nysret Avdiu, “An analysis of Induction motor with Two stator windings connected in Star and Delta connection supply from three phase network." IEEE, PEDES-2006, International Conference on Power Electronics, Drives and Energy Systems for Industrial growth-2006.

[7]. V. Prakasha, S. Baskar, S. Sivakumar and K. Sri Krishna "A novel efficiency improvement measure in three-phase induction motors, its conservation potential and economic analysis" International Energy Initiative, Inc. Published by Elsevier Inc. Vol. 12, June 2008, pp. 78-87

[8]. Benbouzid, M.E.H.; Beguenane, R.; Dessoude, M.; Hubbi, W., "Energy optimized control strategy for a variable input voltage three-phase induction motor" IEEE International conference on Electric Machines and Drives Conference Volume, Issue, 18-21 May 1997 Page(s):MD2/5.1 - MD2/5.3

[9]. Hubert.Razik, Abderrezak Rezzoug, Djafar. Hadiouche "Modelling and Analysis of Dual - Stator Induction Motors", IEEJ Transcations Industrial Applications, Vol. 125,2005 pp. 1093-1104. References and further reading may be available for this article. To view references and further reading you must purchase this article.

[10]. Lilibu, Chunhi, Jeffkrukowski, Wilsun Xu, Xian hiu, “A New Energy Recovery Double Winding Cage-Rotor Induction Machine” IEEE Transactions on Energy Conversion, Vol.18 June 2002, pp. 315 - 320

[11]. Grantham, C. Tabatanaei-Yazdi, H. Rahman, M.F. "A novel method for rapid efficiency measurement of three phase induction motors", IEEE Transaction on Energy Conversion, 1999, Vol. 14, pp. 1236-1240

[12]. Harold J. Weber, “A.C.Induction motor energy conserving power control method and apparatus" US Patent: 4806838, February 21, 1989.

[13]. F.Parasiiti.,M.Viiani, C. Walti., G, Songini., A. Novelto,T. Rossi "Three-Phase Induction motor Efficiency Improvements with Die -cast copper rotor cage and premium steel", SPEEEDAM 2004, June 16-18, CAPRI (Italy).

[14]. C.Thangaraj, S.P.Srivastava and Pramod Agarwal"Energy Efficient Control of Three-Phase Induction Motor-A Review" International Journal of Computer and Electrical Engineering, Vol.1, 2009, pp.61-70

[15]. Al-Ali, AR; Negm, MM; Kassas, M “A PLC Based Power Factor Controller For A 3-Phase Induction Motor" Conference record of the 2000 IEEE Industry applications conference, pp.1065-1072

[16]. Ferreira, F.J.T.E. de Almeida, A.T, "Novel Multiflux Level,Three- Phase, Squirrel-Cage Induction Motor for Efficiency and Power Factor Maximization" Energy Conversion, IEEE Transactions, 2008 Vol:23, pp: 101-109

[17]. Al-Khalaf Bani-Younis, Jihad; Ferrah, Azzeddine; Tami,Abdelkader;Bouzguenda, Munir, "Design of a segment- stator induction motor with optimum efficiency", International Journal of Applied Engineering Research Article, 2008

[18]. R. Kannan, R. Bhuvaneswari,and S. Subramanian, “Optimal Design of Three-Phase Induction Motor Using Particle Swarm Optimization” Iranian Journal of Electrical and Computer Engineering, VOL. 6, 2007 pp 105-111

[19]. Chandrasekaran.V, Manigandan.T, “An InnovativeApproach forEnergy Conservation in Induction Motor”, International Conference on Man-Machine Systems (ICoMMS), 11 - 13, October 2009. Batu Ferringhi, Penag, Malaysia, pp IB2-1 - IB2-

[20]. Yuriy Kats, 'Adjustable speed drives with multiphase motors',IEEE Transaction,1997. 